\title{
Astatine-211 Alpha Radiation
}

National Cancer Institute

\section{Source}

National Cancer Institute. Astatine-211 Alpha Radiation. NCI Thesaurus. Code C129638.

Alpha rays produced by the decay of astatine- 211 . 